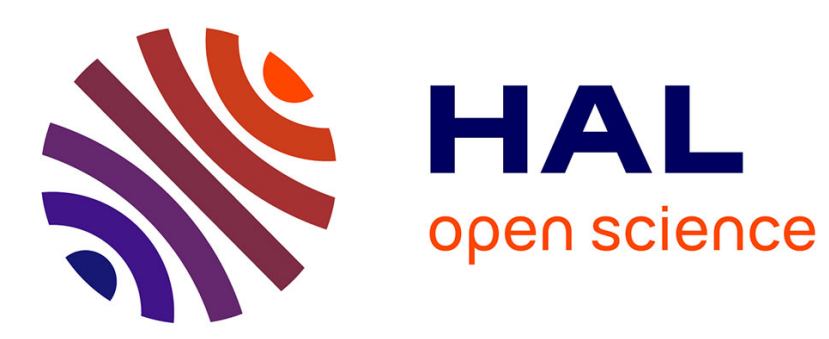

\title{
Stratified flow model for convective condensation in an inclined tube
}

\author{
Stéphane Lips, Josua P. Meyer
}

\section{To cite this version:}

Stéphane Lips, Josua P. Meyer. Stratified flow model for convective condensation in an inclined tube. International Journal of Heat and Fluid Flow, 2012, 36, pp.83-91. 10.1016/j.ijheatfluidflow.2012.03.005 . hal-01470410

HAL Id: hal-01470410 https://hal.science/hal-01470410

Submitted on 20 Mar 2019

HAL is a multi-disciplinary open access archive for the deposit and dissemination of scientific research documents, whether they are published or not. The documents may come from teaching and research institutions in France or abroad, or from public or private research centers.
L'archive ouverte pluridisciplinaire HAL, est destinée au dépôt et à la diffusion de documents scientifiques de niveau recherche, publiés ou non, émanant des établissements d'enseignement et de recherche français ou étrangers, des laboratoires publics ou privés. 


\title{
STRATIFIED FLOW MODEL FOR CO-CURRENT CONVECTIVE CONDENSATION IN AN INCLINED TUBE
}

\author{
Stéphane Lips and Josua P. Meyer* \\ Department of Mechanical and Aeronautical Engineering \\ University of Pretoria \\ Private Bag X20, Hatfield, 0028 \\ South Africa \\ *Email - josua.meyer@up.ac.za
}

\begin{abstract}
Experimental data are reported for condensation of R134a in an $8.38 \mathrm{~mm}$ inner diameter smooth tube in inclined orientations with a mass flux of $200 \mathrm{~kg} / \mathrm{m}^{2} \mathrm{~s}$. Under these conditions, the flow is stratified and there is an optimum inclination angle, which leads to the highest heat transfer coefficient. There is a need for a model to better understand and predict the flow behaviour. In this paper, the state of the art of existing models of stratified two-phase flows in inclined tubes is presented, whereafter a new mechanistic model is proposed. The liquidvapour distribution in the tube is determined by taking into account the gravitational and the capillary forces. The comparison between the experimental data and the model prediction showed a good agreement in terms of heat transfer coefficients and pressure drops. The effect of the interface curvature on the heat transfer coefficient has been quantified and has been found to be significant. The optimum inclination angle is due to a balance between an increase of the void fraction and an increase in the falling liquid film thickness when the tube is inclined downwards. The effect of the mass flux and the vapour quality on the optimum inclination angle has also been studied.
\end{abstract}

Keywords: Two-phase flow modelling, condensation, inclined tube, heat transfer coefficient, pressure drop 


\section{Nomenclature}

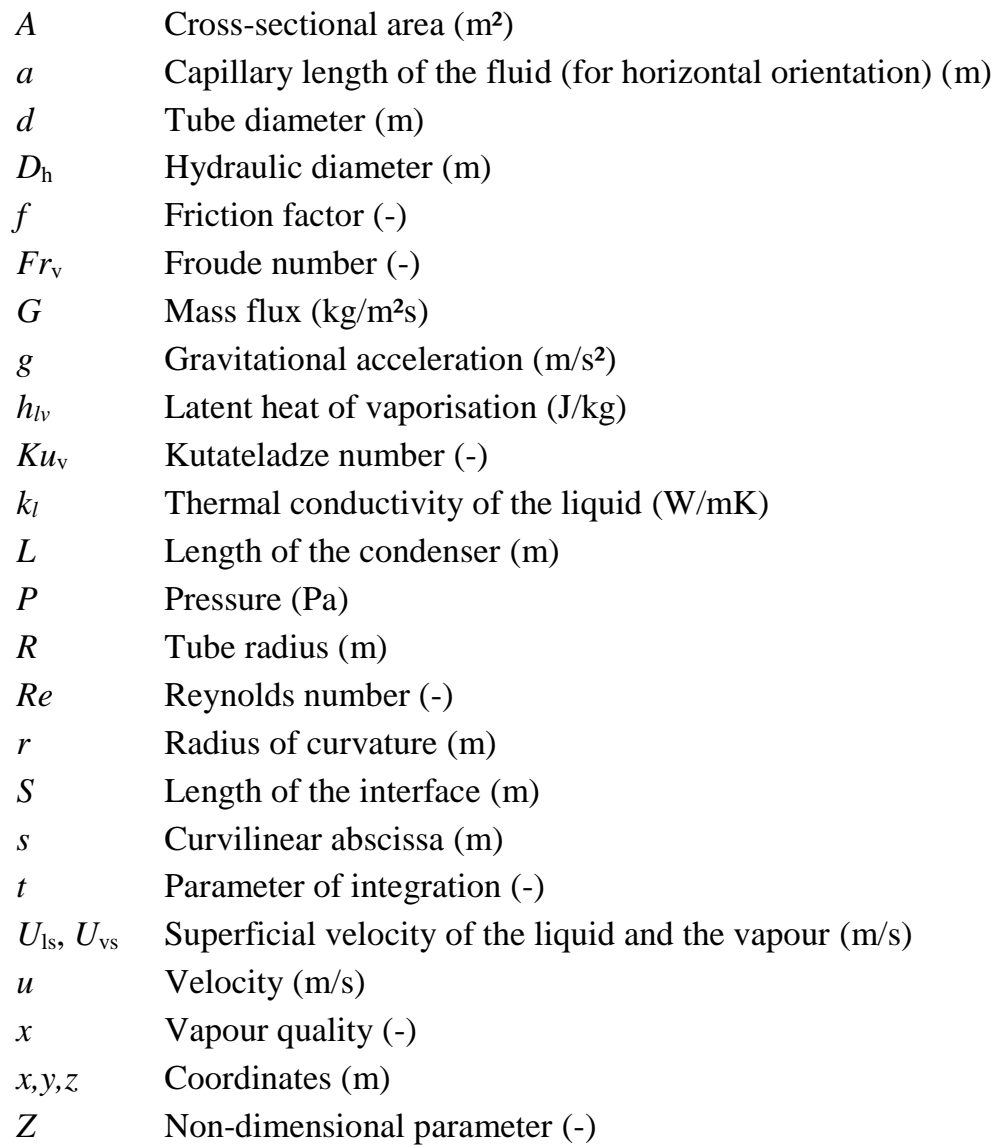

Greek symbols

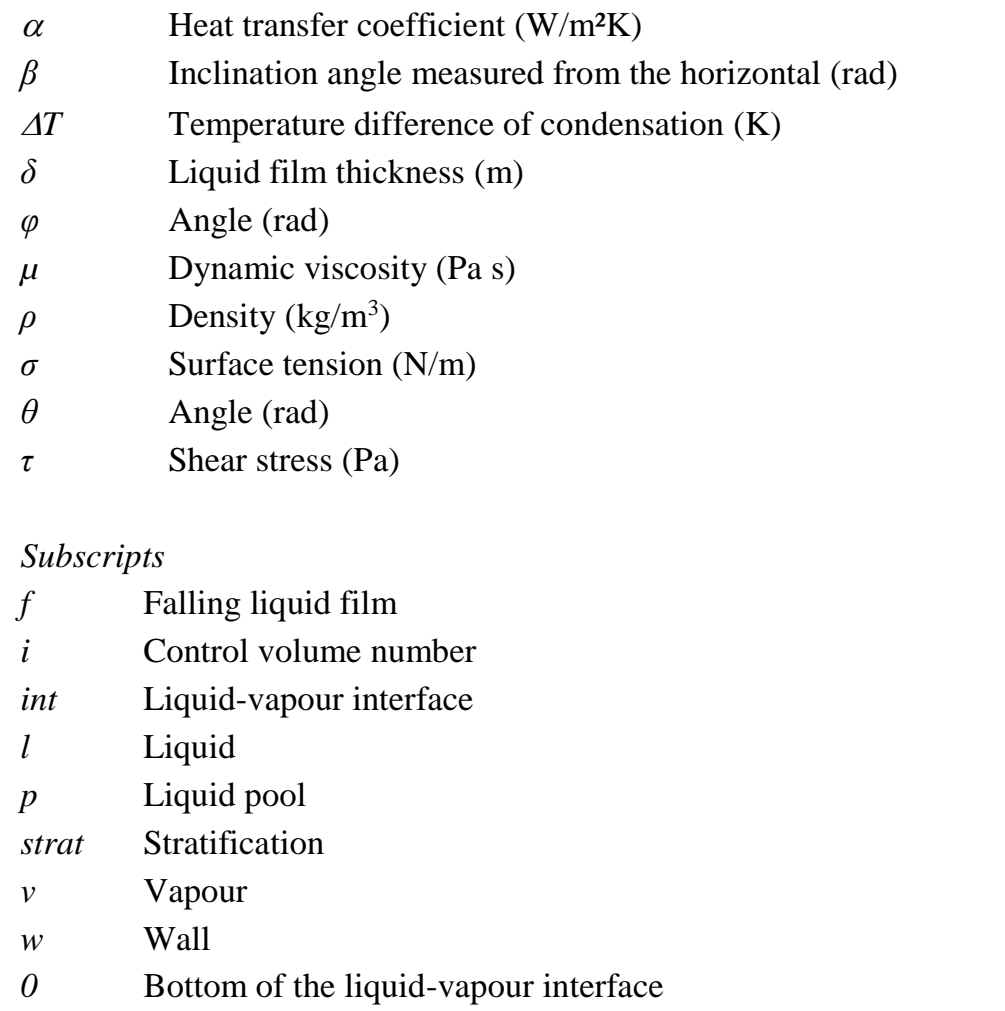




\section{Introduction}

Two-phase flows inside tubes are characterised by their flow pattern, which is the result of the balance between gravitational, shear and capillary forces. The flow pattern influences all the other flow properties such as the pressure drops and the heat transfer coefficients. The pressure drops are strongly dependent on the void fractions. The heat transfer coefficients are strongly dependent on the liquid-vapour distributions in the tube. In a review of two-phase flows in inclined tubes, Lips and Meyer (2011a) showed that the tube inclination angle can have a strong influence on the two-phase flow behaviour. In downward orientations, two-phase flows are always co-current but for upward orientations, counter-current flows can be observed for low mass fluxes in the case of reflux condensation. The present study focuses only on convective condensation, for which the mass flux is high enough for the flow to be co-current, whatever the tube inclination.

Lips and Meyer (2012a) conducted an experimental study during convective condensation and they quantified the flow patterns and the heat transfer coefficients as function of inclination angles. Also the pressure drops and the void fractions (Lips and Meyer, 2012b) were measured as function of inclination angles. It has been shown in these papers that for high vapour qualities and high mass fluxes, the flow is insensitive to gravity, so the traditional models and correlations developed for horizontal or vertical orientations can also be used for inclined orientations. The experimental data of Lips and Meyer (2012a, 2012b) were also used to develop flow regime maps (Lips and Meyer, 2011b) of the gravity effect on the flow patterns, heat transfer coefficients and apparent void fractions. It constituted the first step of the development of models or correlations to predict the limit between gravity-dependent and gravity-non-dependent flows. For low mass fluxes, the flow is gravitydependent and is mainly stratified for downward flows and mainly intermittent for upward flows. However, no model is widely accepted in the literature for these types of flow patterns as function of inclination angles.

The present paper aims to fill this limitation in terms of stratified flows. The state of the art of the stratified two-phase flow models in inclined tubes is conducted and experimental results are presented in order to highlight the different phenomena that need to be taken into account in these models. Then, a new model, coupling a hydrodynamic and a thermal model, is presented. Lastly, a comparison is made between the model predictions and the experimental results. Furthermore, the model is used to determine the trends of the mass flux and vapour quality on the heat transfer coefficient as function of inclination angle.

\section{Literature review of stratified flow models during condensation}

In the literature, two ways of studying convective condensation can be found. Some authors consider a complete condensation: the refrigerant is vapour at the beginning of the test section and liquid at the end. However, the properties of the two-phase flow significantly change with the vapour quality.Studying complete condensation in detailrequires a lot of measurement stations along the test section in order to not miss phenomena caused by averaging the different studied parameters. The opposite is, that other authors consider only a "local" or "partial" condensation process: They impose an average vapour quality in the test section and observe the properties of the condensing flow for a very small vapour quality variation across the test-section. A clear limitation of this kind of experiments is that they do not represent exactly what would happen in a real world application. However, studying a partial condensation makes it possible to determine in more detail the vapour quality effect on the condensing flow properties. 
This literature review focuses on the hydrodynamic modelling of gas-liquid flow and on the thermal modelling of separated condensing flow but furthermore specifically concentrates on local values . As a consequence, Computational Fluid Dynamics models, which are more and more used to model a complete condensation, are not considered in the present study.

\subsection{Hydrodynamic modelling of gas-liquid separated flows in inclined tubes}

In order to develop a model for stratified flow during condensation, the first step is to determine the liquidvapour distribution in the tube. This is the development of the liquid film thickness along the tube perimeter. Some models developed for adiabatic gas-liquid flows were often the source of more recent models taking into account the condensation process. For example, the flow pattern map of Taitel and Dukler (1976) is based on a model of stratified flow where the liquid-vapour interface is supposed to be flat. The model was developed for slightly inclined tubes and the liquid hold-up is determined by equalising the pressure drops in the liquid and in the vapour. Some improvements, mainly in the calculation of the shear stresses, were proposed by different authors. Spedding et al. (1998) summarised some of these models and compared their results with an experimental database of air-water flow in slightly inclined tubes. However, Ullmann et al. (2003) showed theoretically and experimentally that several liquid hold-ups can occur during certain conditions, which makes the study of this kind of flow more complex.

Grolman and Fortuin (1997) showed that the assumption of considering a smooth interface, as in the model of Taitel and Dukler, leads to an unacceptable error for upward flows. They developed a semi-empirical model taking into account an equivalent relative roughness to calculate the interfacial friction factor. The fact that the liquid-vapour interface is flat was under certain conditions not verified. For instance, the curvature interface and the wetted perimeter of the tube increased gradually with increasing gas and liquid flow rates. Fukano and Ousaka (1989) explained the increase of the curvature as a consequence of the presence of secondary flows in the gas phase, the liquid deposition at the top of the tube by entrainment and because of the pumping action of the waves in the liquid pool. Laurinat et al. (1985), and later Fukano and Ousaka (1989), developed some models to take these phenomena into consideration.

For low mass fluxes, the liquid-vapour interface is not flat when the capillary forces are of the same order of magnitude as that of the gravitational forces. This can occur for small tubes, for high inclination angles or for a low difference of density between the liquid and the vapour phases. Brauner et al. $(1996,1998)$ predicted the curvature of an interface by assuming that the interface configuration corresponds to the minimum of the potential and surface energy. Wang and $\mathrm{Du}$ (2000) performed a similar study but added the kinetic energy in the system energy.

Only a few experimental results of stratified flows in inclined tubes were published (Fukano and Ousaka, 1989; Hetsroni et al., 2003; Geraci et al., 2007) and the results often contradict each other (Lips and Meyer, 2011a). However, in all these papers, the liquid-vapour interface has been found to have a high curvature. It highlights the need to take into account this curvature in a new model.

\subsection{Thermal modelling of separated condensing flows}

Models specific to condensing flows have been developed and they can be classified into two types: falling film and liquid pool models and continuous liquid film models. The first type of model is directly based on 
Taitel and Dukler's (1976) type of stratified model. A liquid pool is assumed to be located at the bottom of the tube and its properties are calculated by means of an adiabatic liquid-gas flow model. A falling liquid film is present on the upper part of the tube and its thickness is derived from Nusselt's (1916) theory in order to calculate the heat transfer coefficient. Nitheanandan and Soliman (1994) developed a similar model to predict the effect of the condensation on the transition between stratified and non-stratified flows in inclined tubes. They concluded that the condensation process had the same effect than that of a small increase in the inclination angle. Fiedler and Auracher (2004) proposed a model for condensation inside inclined thermosyphons. Recently, Saffari and Naziri (2010) published a numerical falling film and liquid pool model for condensation. Their model was able to predict the maximum heat transfer coefficient in an inclined tube from $30^{\circ}$ to $50^{\circ}$. However, a limitation of all these models is that the liquid-vapour interface is supposed to be flat, which was not verified experimentally for small tubes or for high inclination angles.

The second type of model is based on a single continuous liquid film, whose form is determined from a balance between the gravitational, capillary and shear forces, taking into account the condensation process. Fieg and Roetzel (1994) presented an analytical solution of laminar film condensation on inclined elliptic tubes, using Nusselt's (1916) theory. The solution can also be used for condensation inside tubes. Hussein et al. (2001) proposed a numerical model, also derived from Nusselt's theory, but for an application of condensation in thermosyphons. In the model, a steady-state two-dimensional model is solved to determine the liquid film thickness. Both in the Fieg and Roetzel (1994) and in the Hussein et al. (2001) models, gravitational and shear forces are taken into account but capillary forces are neglected. A major assumption of these models is that the liquid film thickness is supposed to be small compared with the tube radius. These models are relevant for twophase flows with high void fractions but do not represent satisfactory flows at low void fractions.

Other approaches were used to calculate the liquid film thickness around the tube perimeter. For instance, Wang and Du (2000) conducted a theoretical and experimental study of laminar film-wise condensation of water vapour in a small inclined tube in downward inclinations. They developed a numerical model to predict the shape of the liquid-vapour interface by calculating the interface curvature angle as a result of the minimum energy principle. Potential, kinetic and surface energies were taken into consideration. However, there is no widely accepted method to calculate these energies in the literature and the validity of the minimum energy principle can thus be questioned. Mechanistic models have also been developed for condensation in microchannels. For instance, Wang and Rose (2006) developed a condensation model for inclined square channels with sides between 0.5 and $3 \mathrm{~mm}$. Under these conditions, the capillary forces are dominant and the shape of the liquid-vapour interface is determined by including the effect of the surface tension and the surface curvature. However, the model developed for microchannels cannot be extrapolated to minichannels as the order of magnitude of the capillary forces compared with the gravitational forces is different.

In conclusion, it appears that the falling film and liquid pool models considering a flat liquid-vapour interface were adapted for condensation in large tubes (compared with the capillarity length of the fluid) and for slightly inclined tubes. The models considering the capillary forces as the dominant forces were valid for small tubes only. Thus, there is a need for models taking into account both the gravitational forces and the capillary forces in order to fill the gap that exists between the two previous types of models. The model presented in this paper aims to be a falling film and liquid pool model, but taking into account the curvature of the liquid-vapour 
interface. The next section highlights the need for considering a curved interface by examining some experimental results.

\section{Experimental results}

Measurements were obtained with a condensation experimental set-up described in Lips and Meyer (2012a, $2012 b)$. Heat transfer coefficients and flow patterns were recorded for a condensing flow in an inclined smooth tube with an inner diameter of $8.38 \mathrm{~mm}$ and a length of $1.488 \mathrm{~m}$. The test section consisted of a tube-in-tube counterflow heat exchanger, with water in the annulus and refrigerant in the inner tube. Refrigerant R134a was used with a saturation temperature of $40^{\circ} \mathrm{C}$. Experiments used in the present study were conducted for a mass flux of $200 \mathrm{~kg} / \mathrm{m}^{2} \mathrm{~s}$ at different mean vapour qualities in the quality ranges of 0.1-0.9 and for different inclination angles, from vertical downward to vertical upward orientations. The heat transfer rate in the condenser was controlled by varying the cold water mass flux and temperature. It was kept constant to $5.1 \mathrm{~kW} / \mathrm{m}^{2}$, which corresponds to a vapour quality variation of about 0.11 . Other experimental results were presented in Lips and Meyer (2012a, 2012b) with higher heat fluxes but they are not used in the present study because they corresponds to experimental conditions for which the flow is no longer stratified.

Fig. 1 summarises the experimental results as function of heat transfer coefficients. Inclination angles lower and higher than zero represent downward and upward flows respectively. The inclination angle affects the heat transfer coefficients mainly at low vapour qualities while an optimum inclination angle, which leads to the highest heat transfer coefficient, is found to be between $-15^{\circ}$ and $-30^{\circ}$.

The fact that there is an optimal heat transfer coefficient can be explained by the influence of the inclination angle on the flow pattern. Fig. 2 represents the experimental flow pattern map obtained for $G=200 \mathrm{~kg} / \mathrm{m}^{2} \mathrm{~s}$. The flow patterns are represented as a function of the inclination angle and the vapour quality. The distinction is made between five flow patterns: stratified-wavy, annular, annular-wavy, intermittent, and churn flows. Intermittent flows regroup plug flows and slug flows. Annular-wavy flow occurs when there is a thick liquid film with ripples or waves at the top of the tube, but with the liquid mainly located at the bottom of the tube. For $G=200 \mathrm{~kg} / \mathrm{m}^{2} \mathrm{~s}$, stratified-wavy flows occur mainly for downward orientations. The present study will thus focus on these experimental conditions.

Fig. 3 represents some photos from a video of the flow in downward orientations for different void fractions and different inclination angles. Tilting the tube leads to a decrease of the liquid cross-sectional area and thus to an increase of the heat transfer coefficient because of the decrease of the flooded perimeter. The flooded perimeter is the part of the tube perimeter occupied by the liquid pool at the bottom of the tube. The heat transfer is very small along the flooded perimeter because of the high thickness of the liquid film. There is a minimum in terms of flooded perimeter for an inclination angle of about $-45^{\circ}$. For sharper inclination angles, the decrease of the gravity forces perpendicularly to the tube tends the flow to become more and more annular. However, this minimum of the flooded perimeter at about $-45^{\circ}$ does not correspond to the maximum of the heat transfer coefficient, which occurs between $-15^{\circ}$ and $-30^{\circ}$. Thus, a model is necessary to understand and to predict the maximum heat transfer coefficients encountered in these experiments.

\section{Thermohydraulic model}

\subsection{Determination of the stratified flow condition}


The first step of the model development is to determine if the flow is stratified, or not, in order to have an idea of the validity of the assumptions and thus of results. In the literature, two flow pattern maps for two-phase flows in inclined tubes are available for the whole range of inclination angles: the flow pattern map of Barnea (1987) and the flow pattern of Crawford et al. (1985). The flow pattern map of Barnea (1987) uses the criterion of Taitel and Dukler (1976) for the stratified-non-stratified transition. However, Lips and Meyer (2012a) showed that this criterion highly underestimated the mass flux for which the transition occurs. Thus, the transition limit of Crawford et al. (1985) is used in the present study. Both conditions $U_{\mathrm{ls}}<U_{\mathrm{ls} \text {,annular }}$ and $U_{\mathrm{ls}}<U_{\mathrm{ls} \text {,separated }}$ must be verified for the flow to be stratified. $U_{\mathrm{ls}}$ is the superficial velocity, defined as $U_{\mathrm{ls}}=G(1-x) / \rho_{\mathrm{l}}$. $U_{\mathrm{ls} \text {,annular }}$ and $U_{\mathrm{ls}, \text { separated }}$ are defined respectively as:

$$
U_{i g_{i} \text { annular }}=U_{w S}\left(\frac{1.9}{K u_{V}^{0.2} F r_{V}^{0.18}}\right)^{g}
$$

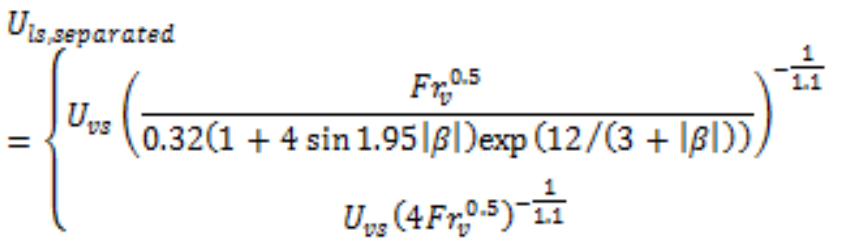

for downward flows

\section{for horizontal and slightly upward flows}

with $U_{\mathrm{vs}}=G x / \rho_{\mathrm{v}}, F r_{\mathrm{v}}=U_{\mathrm{vs}}{ }^{2} /(g d), K u_{\mathrm{v}}=U_{\mathrm{vs}} \rho_{\mathrm{v}}{ }^{2} /\left(\mathrm{g}\left(\rho_{\mathrm{l}-} \rho_{\mathrm{v}}\right) \sigma\right)^{0.25}$ and $\beta$ is in degrees. Stratified flow cannot occur for sharply inclined upward flows. Crawford et al. (1985) do not give any criterion for the inclined angle, so a limit of $20^{\circ}$ was chosen for this paper, which corresponds to the maximum inclination angle (Fig. 2) for which stratified flow occurs at a mass flux of $200 \mathrm{~kg} / \mathrm{m}^{2} \mathrm{~s}$.

The flow pattern of Crawford et al. (1985) is drawn in Fig. 4 for R134a at a saturation temperature of $40^{\circ} \mathrm{C}$ flowing in an $8.38 \mathrm{~mm}$ inner diameter tube and for different inclination angles. The boundaries of the annular flow regime are independent of the inclination angle, which is not the case for the transition between the stratified and the intermittent flow regimes. For downward flow, the stratified flow regime is dominant for low vapour qualities whereas for upward flows, the intermittent flow regime is dominant. Even if the accuracy of the flow pattern of Crawford et al. (1985) can be discussed regarding our experimental data, it gives a good order of magnitude of the flow regime transitions.

\subsection{Hydrodynamic model}

The hydrodynamic model is based on the model of Taitel and Dukler (1976), but taking into consideration a curved interface. The first step is then to calculate the shape of this interface, depending on the experimental conditions, in order to include it in the model of Taitel and Dukler (1976).

\subsubsection{Shape of the liquid-vapour interface (Fig. 5).}

In the present study, the shear forces are neglected in the determination of the shape of the liquid-vapour interface. This assumption is verified for stratified flows, which are mainly dominated by the gravitational forces. Under these conditions, the shape of the liquid-vapour interface is led by gravitational and capillary forces only.

The Young-Laplace law introduces capillary pressure forces onto the curvature radius $r(z)$ at each point of the meniscus. By neglecting the meniscus curvature along the $y$-axis, the pressure in the liquid can be expressed as: 


$$
P_{1}(z)=P_{V}-\frac{\sigma}{r(z)}
$$

The axis $z=0$ is located at the bottom of the interface, at the distance $z_{0}$ from the centre of the tube. $z_{0}$ can be positive or negative, depending on the void fraction in the flow. As the tube is inclined, gravitational forces induce:

$$
P_{1}(z)=\left(\rho_{l}-\rho_{v}\right) g \cos \beta z+P_{1}(z=0)
$$

By introducing Eq. (3) in Eq. (4), and by noting $r_{0}$ the radius of curvature of the interface at $z=0$, capillary and gravitational forces are linked together:

$$
\frac{\sigma}{r_{0}}-\frac{\sigma}{r(z)}=\left(\rho_{0}-\rho_{v}\right) g \cos \beta z
$$

Equation (5) can be written as:

$$
r(z)=\frac{1}{\frac{2 z}{a^{2}}+\frac{1}{r_{0}}} \text { with } a^{2}=\frac{2 \sigma}{\left(\rho_{l}-\rho_{b}\right) g \cos \beta}
$$

If $\beta=0, a$ is the so-called capillary constant of the fluid. Let us introduce the angle $\varphi$ between the tangent to the meniscus and the $x$-axis. The meniscus curvature radius can be expressed as:

$$
r(z)=\frac{d z}{\sin \varphi d \varphi}
$$

By introducing Eq. (6) in Eq. (7), we obtain:

$$
\left(\frac{2 z}{a^{2}}+\frac{1}{r_{0}}\right) d z=\sin \varphi d \varphi
$$

Considering the boundary limit $\varphi=0$ for $z=0$, the integration of Eq. (8), leads to:

$$
\left(\frac{z}{a}\right)^{2}+\frac{z}{r_{0}}=1-\cos \varphi
$$

The shape of the liquid-vapour interface can be deduced from Eq. (9) by means of a numerical model with an explicit scheme. The interface is described by the points $\mathrm{M}_{\mathrm{i}}\left(x_{\mathrm{i}}, z_{i}\right)$ and is divided into segment of length $d s$, where $s$ is the curvilinear abscissa. The initial condition, $z=0$ and $\cos \varphi=0$ for $x=0$, induces that $z_{1}=z_{2}=0$. We also have $x_{1}=0$ and $x_{2}=d s$. For $x=0$, we assume a known $r_{0}$, so we can calculate $x_{3}$ and $z_{3}$ with the expression of the radius of curvature and the derivatives with the finite difference method. Then, for each point $\mathrm{M}_{\mathrm{i}}$, Eq. (9) allows calculating $\varphi_{\mathrm{i}}$, and thus $\mathrm{M}_{\mathrm{i}+1}\left(x_{\mathrm{i}+1}, z_{\mathrm{i}+1}\right)$ from:

$$
d x=\mathrm{x}_{\mathrm{i}+1}-\mathrm{x}_{\mathrm{i}}=\cos \varphi d s \text { and } d z=\mathrm{z}_{\mathrm{i}+1}-\mathrm{z}_{\mathrm{i}}=\sin \varphi d s
$$

We assume a perfect wettablity of the liquid, it means a contact angle equal to zero between the liquidvapour interface and the wall. Thus, at the point of the interface that is located on the wall, $\mathrm{M}_{\mathrm{w}}\left(x_{\mathrm{w}}, z_{\mathrm{w}}\right)$, we have $\cos \varphi=\left(z_{0}-z_{W}\right) / R$, the tube centre coordinates being $\mathrm{O}\left(0, z_{0}\right)$. To satisfy this boundary condition, an iterative method is used by varying $r_{0}$ until the liquid-vapour interface and the tube wall are tangent. With this model, it is thus possible to determine the shape of the liquid-vapour interface from a given $z_{0}$.

\subsubsection{Flow and pressure drop modelling (Fig. 6).}

To determine the velocity of each phase, the pressure drop and the void fraction in the flow, a modified model of Taitel and Dukler (1976) is used. In this model, the shape of the liquid-vapour interface is determined by the model previously described in the section.

In steady-state separated flow, the following two momentum equations are satisfied: 
$A_{w}\left(-\frac{d P}{d L}\right)_{w g}=\tau_{w w} S_{w}+\tau_{i v} S_{i n t}+A_{w} \rho_{v} g \sin \beta$

$A_{\mathbb{P}}\left(-\frac{d P}{d L}\right)_{\mathbb{Q}}=\tau_{\mathbb{W}} S_{\mathbb{l}}-\tau_{i} S_{\text {int }}+A_{\mathbb{Q}} p_{\mathbb{1}} g \sin \beta$

The model is based on the force balance between the pressure drop in the liquid and in the vapour phase. Combining Eqs. (11) and (12), the equation to solve becomes:

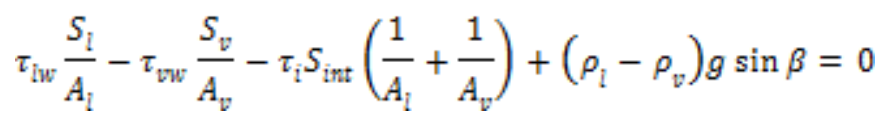

The shear stresses are calculated using the conventional manner described by Taitel and Dukler (1976):

$\tau_{\mathrm{WW}}=f_{\mathrm{I}} \frac{\rho_{\mathrm{Q}} u_{\mathrm{i}}^{2}}{2}$ and $\tau_{\mathrm{WW}}=\tau_{i}=f_{\mathrm{V}} \frac{\rho_{\mathrm{W}} u_{W}^{2}}{2}$

with:

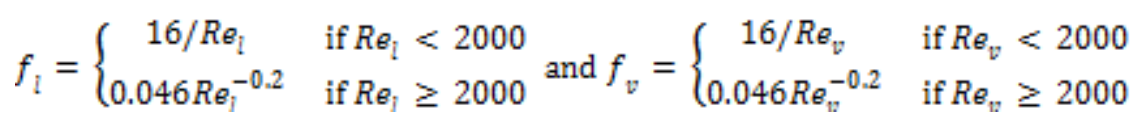

The Reynolds number is defined as:

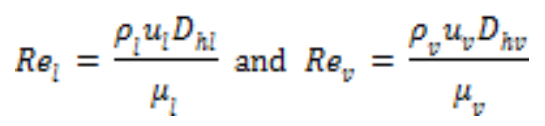

with

$D_{h \mathbb{l}}=\frac{4 A_{\mathbb{1}}}{S_{\rrbracket}}$ and $D_{h w}=\frac{4 A_{v}}{S_{v}+S_{i}}$

The difference with the original model is that the geometrical parameters $A_{\mathrm{l}}, A_{\mathrm{v}}, S_{\mathrm{l}}, S_{\mathrm{g}}, S_{\mathrm{i}}$ are numerically calculated by means of the model of the shape of the liquid-vapour interface. As a result, this model allows the determination of all the parameters in Eq. (13) as a function of $z_{0}$ and an iterative method is used to solve the Eq. (13). The expression of the shear stresses (Eq. (14)), the friction factors (Eq. (15)) and the hydraulic diameters (Eq. (17)) is often the subject of intense discussions in the literature. The present form assumes that the vapour velocity is much higher than the liquid velocity, which is often the case in two-phase flow. However, it is good to keep in mind that these expressions must be considered only as an approximation of the calculation of the shear stresses. The impact of this approximation is discussed in section 5.3. The hydrodynamic model allows the calculation of the pressure drop and of the liquid distribution at the bottom of the tube, and especially the calculation of the flooded perimeter and the liquid film thickness, depending on the experimental conditions.

\subsection{Thermal model}

Once the liquid distribution is known, a thermal model can be used to calculate the heat transfer coefficient. The tube perimeter is divided into two parts (Fig. 7) to take into account different phenomena in the falling liquid film $\left(\theta<\theta_{\text {strat }}\right)$ and in the liquid pool at the bottom of the tube $\left(\theta>\theta_{\text {strat }}\right)$.

\subsubsection{Falling liquid film.}

The theory of Nusselt (1916) can be used to calculate the liquid film thickness and thus the heat transfer coefficient at the upper part of the tube. Fieg and Roetzel (1994) give the analytical solution of the Nusselt theory for an inclined tube. The local film thickness can be written as: 


$$
\delta(\theta)=\left(\frac{3}{2} \frac{\mu_{l} \Delta T k_{l} d}{\rho_{l}\left(\rho_{l}-\rho_{V}\right) g h_{l v} \cos \beta} Z\right)^{1 / 4}
$$

where $Z$ is a function of $\theta$ and is equal to:

$$
Z=\frac{4}{3} \frac{1}{\sin ^{4 / a} \theta} \int_{0}^{\theta} \sin ^{1 / a} t d t
$$

From the local thickness, it is possible to calculate the local heat transfer, $\alpha(\theta)=k_{1} / \delta(\theta)$, and thus to determine an average heat transfer coefficient, $\overline{\alpha_{f}}$, for the upper part of the tube.

$$
\overline{a_{f}}=\frac{1}{\theta_{\text {atrat }}} \int_{0}^{\theta_{s t r a t}} \frac{k_{1}}{\delta(\theta)} d \theta
$$

\subsubsection{Liquid pool}

At the bottom of the tube, the shape of the liquid pool is calculated by means of the hydrodynamic model. To determine an approximation of the heat transfer coefficient in this area, convection is neglected and the heat conduction is assumed to occur locally in the direction perpendicular to the liquid-vapour interface. The liquid pool is divided into trapezoidal control volumes (Fig. 7) and the local heat transfer coefficient of each control volume, $a_{p, i}$, is determined using the approximation of the heat transfer in cylindrical coordinates. The surface of reference for the determination of the heat transfer coefficient is the tube wall surface, $d s_{\mathrm{wwi} i}$.

$$
a_{p, i}=\frac{\left(d s_{w_{i}, i}-d s\right) k_{\mathbb{I}}}{d s_{w_{i} i} \delta_{i} \ln \left(d s_{w_{i}} / d s\right)}
$$

where $\delta_{i}$ is the local thickness, calculated perpendicularly to the liquid-vapour interface. Close to the intersection of the meniscus with the wall, the liquid film thickness is assumed to be at least equal to the falling film thickness calculated for $\theta=\theta_{\text {strat }}$. The average heat transfer coefficient of the liquid pool is then calculated by:

$$
\overline{\alpha_{p}}=\frac{1}{\sum d s_{w, j}} \sum \alpha_{p, i} d s_{w, i}
$$

In practice, $\overline{\alpha_{p}} \ll \overline{\alpha_{f}}$, so the assumption of unidirectional conduction perpendicularly to the interface with a cylindrical approximation of the trapezoidal control volumes is acceptable. Finally, the global average heat transfer coefficient of the tube is equal to:

$$
\bar{\alpha}=\frac{\overline{\alpha_{f}} \theta_{s t r a t}+\overline{\alpha_{p}}\left(\pi-\theta_{s t r a t}\right)}{\pi}
$$

The thermal model, coupled with the hydrodynamic model, allows the determination of the global heat transfer coefficient in the tube, from the experimental conditions and the fluid properties. One of the strengths of the present model is that no empirical parameter or correlation is required. However, to be validated, the model predictions need to be compared with experimental results.

\section{Results and discussion}

\subsection{Shape of the liquid-vapour interface}

The first step to achieve a good understanding of the inclination effect on the stratified flow properties is to study the development of the liquid-vapour distribution as a function of the inclination angle. Fig. 8 presents the model predictions of the model in terms of the flooded angle ( $\left.\theta_{\text {flooded }}\right)$ and liquid hold-up $\left(z_{0}\right)$ for a mass flux of $250 \mathrm{~kg} / \mathrm{m}^{2} \mathrm{~s}$ and for three different void fractions $(x=0.3,0.5$ and 0.7$)$. The flooded angle corresponds to the 
angle occupied by the liquid pool and is equal to $\theta_{\text {flooded }}=2\left(\pi-\theta_{\text {strat }}\right)$. Some graphs of the liquid-vapour interface are also plotted for four inclination angles from $-75^{\circ}$ to $+15^{\circ}$. When the results are presented in dashed lines, it means that the experimental conditions do not correspond to a stratified flow according to the transition of Crawford et al. (1985). These experimental conditions were considered in order to study the limits of the model. As expected, the liquid hold-up decreases continuously when the tube is inclined in downward position because the liquid velocity increases and thus the void fraction increases as well. However, the strongest variation of the hold-up seems to occur for slightly upward flow $\left(0^{\circ}<\beta<10^{\circ}\right)$. In practice, the model is not valid under these conditions, but it explains why the flow is intermittent in the upward orientation even for low inclination angles. The behaviour of the flooded perimeter is different from that of the liquid hold-up. There is a plateau between $60^{\circ}$ and -30 for which the flooded angle is minimal for a large range of inclination angles. The actual minimum occurs for about $-45^{\circ}$, which is consistent with the experimental observations (Fig. 3). For inclination angle lower than $-60^{\circ}$, the flooded perimeter increases again because of the increase of the curvature of the interface. This is clearly visible in the graphs plotted for $-75^{\circ}$ and $-45^{\circ}$ in Fig. 8. This figure also shows the effect of the vapour quality on the liquid-vapour distribution. As expected, the level of liquid at the bottom of the tube decreases when the vapour quality increases, but the vapour quality has a relatively low effect on the liquidvapour distribution for downward flows (except at the asymptotes $x=0$ and $x=1$, which are not represented on the graph).

Fig. 9 is the same type of graph as Fig. 8, but for a vapour quality of 0.5 and for three different mass fluxes, $\mathrm{G}=100,150$ and $200 \mathrm{~kg} / \mathrm{m}^{2} \mathrm{~s}$. It is interesting to note that for horizontal flows, the liquid-vapour interface position does not depend on the mass flux. For upward flows, increasing the mass flux leads to a decrease in the liquid hold-up but it is the contrary for downward flows. However, for $100 \mathrm{~kg} / \mathrm{m}^{2} \mathrm{~s}<G<200 \mathrm{~kg} / \mathrm{m}^{2} \mathrm{~s}$, we can conclude that the mass flux has a very low effect on the liquid-vapour distribution in the tube for downward flows.

\subsection{Heat transfer coefficient}

The comparison between the experimental results and the model predictions in terms of heat transfer coefficient is presented in Fig. 10 for a mass flux of $200 \mathrm{~kg} / \mathrm{m}^{2} \mathrm{~s}$ and for different vapour qualities. Note that, as the heat transfer rate is constant for all experiments, the temperature difference of condensation varies from one experiment to another. The temperature difference of condensation is one of the inputs of the model (Eq. (18)). In Fig. 10, where the model predictions are plotted with dashed lines, it shows that the experimental conditions do not correspond to a stratified flow according to the transition of Crawford et al. (1985). However, there is a very good agreement between the experiments and the model predictions for downward flows $(\beta<0)$, and even for high vapour qualities, which do not correspond to a stratified flow according to Crawford et al. (1985). For upward flows, the disturbances due to the waves of the liquid-vapour interface become too important. The flow becomes intermittent (see Fig. 2) and the model is not valid in these conditions.

It is interesting to use the model to determine the importance of the phenomena inducing the presence of an optimal heat transfer coefficient that leads to the highest heat transfer coefficient. Fig. 11 presents the model prediction for $x=0.3, G=200 \mathrm{~kg} / \mathrm{m}^{2} \mathrm{~s}$ and $\Delta T=2 \mathrm{~K}$, and for three different assumptions: (a) The interface is supposed to be flat and the heat transfer coefficient of the falling film of condensation is constant and equal to heat transfer coefficient in a horizontal orientation. (b) The curvature of the interface is taken into account but 
the heat transfer coefficient of the falling film remains constant. (c) The present model, with a curved interface and a varying falling film heat transfer coefficient. The assumption of (a) would lead to a continuous increase of the heat transfer coefficient when the tube is tilted in a downward orientation: this is due to the fact that the void fraction continuously increases and thus $\theta_{\text {strat }}$ increases. Taking into account the curvature of the interface leads to an optimal inclination angle of about $45^{\circ}$. If the inclination angle is higher than $45^{\circ}$, the decrease of the gravitational force component perpendicularly to the tube induces an increase of $\theta_{\text {strat }}$ despite the fact that the void fraction still increases for higher inclination angles. This is confirmed experimentally by Fig. 3 , where $45^{\circ}$ appears to be the orientation that leads to the smallest flooded perimeter and thus to the highest $\theta_{\text {strat }}$. The difference in the results between the assumptions of (b) and the model (assumption (c)) highlights the importance of the effect of gravity on the thickness of the falling liquid film. Tilting the tube too much reduces the drainage of the falling liquid film to the bottom of the tube and thus increases its thickness. It leads to a reduction of the global heat transfer coefficient. According to Eqs. (18)-(20), the average heat transfer coefficient of the falling liquid film is proportional to $(\cos \beta)^{1 / 4}$. As a result, the optimum inclination angle appears to be about $20^{\circ}$ in a downward orientation.

Fig. 12 represents the numerical simulation of the effect of the mass flux on the heat transfer coefficient for $x=0.3$. An increase of the mass flux with a constant vapour quality leads to a decrease of the global heat transfer coefficient because of the decrease of the void fraction. This trend is verified only for stratified flows, when the effect of convection in the heat transfer is negligible. For higher mass fluxes, an increase of the mass flux induces an increase in the heat transfer coefficient due to the increase of the convection. This is verified for a horizontal orientation using the model of Thome et al. (2003) or the correlation of Cavallini et al. (2006). The optimum inclination angle is slightly dependent on the mass flux. An increase of the mass flux induces an increase of the optimum inclination angle, in absolute value. Fig. 13 represents the numerical simulation of the effect of the vapour quality on the optimum heat transfer coefficient: an increase of the vapour quality leads to a decrease (in absolute value) of the optimum inclination angle. However, whatever the mass flux and the vapour quality, the optimum inclination angle remains between -15 and $-25^{\circ}$. This kind of result can be very useful in the design of inclined condensers. Note that in Figs 12 and 13, the numerical simulations plotted in dashed lines corresponds to inclinations that do not correspond to a stratified flow and are probably not realistic.

\subsection{Pressure drops}

Even if the main goal is to predict the heat transfer coefficient, the model is able to calculate the pressure drop in the flow. Fig. 14 presents a comparison of the model predictions (lines) with the experimental pressure drops (markers) presented in Lips and Meyer (2012b) for a mass flux of $200 \mathrm{~kg} / \mathrm{m}^{2} \mathrm{~s}$ and for three vapour qualities. When the model predictions are plotted with dashed lines, it means that the experimental conditions do not correspond to a stratified flow according to the transition of Crawford et al. (1985). When the flow is stratified (solid lines), we observe a good agreement between the model and the experimental results but there is a strong deviation as soon as the flow is no longer stratified (dashed lines). More experimental results are required to validate the hydrodynamic model, especially for other mass fluxes, but the good agreement between the model predictions and the experiments tends to show that the assumptions chosen in the model are probably realistic for the considered experimental conditions. It seems that a simplified model of the interfacial shear stress is enough to predict the global properties of the flow and that the shear forces have a small effect on the 
liquid-vapour distribution in the tube as gravitational and capillary forces are dominant for stratified two-phase flow in inclined tubes. For flows that cannot be considered as stratified, another type of modelling is required to predict the pressure drops.

\section{Conclusions}

A new mechanistic model of stratified condensing flow in inclined tubes has been proposed. A liquid pool with a curved interface at the bottom of the tube, and a falling liquid film at the top of the tube are taken into account. The model aims to fill a gap found in the literature for the modelling of configurations for which the assumption of a flat interface is not verified and for which the gravitational and the capillary forces have the same order of magnitude. The comparison between the experimental results and the model predictions showed a good agreement as long as the criterion of stratified flow of Crawford et al. (1985) is valid. One of the characteristics of the model is that no empirical parameter or correlation is used. The analysis of different assumptions in the numerical model highlighted the importance of taking into consideration the curvature of the liquid-vapour interface as well as the importance of the development of the liquid film thickness with the inclination angle. In order to fully validate the model and to determine its limits of validity, more experimental results are required, with different fluids, different mass fluxes and different tube diameters. Moreover, there is also a need for a model of intermittent flows in upward tubes in order to fully understand the effect of gravitational forces on inclined two-phase flows.

\section{Acknowledgements}

The funding obtained from the NRF, TESP, Stellenbosch University/University of Pretoria, SANERI/SANEDI, CSIR, EEDSM Hub and NAC is acknowledged and duly appreciated.

\section{References}

Barnea, D., 1987. A unified model for predicting flow-pattern transitions for the whole range of pipe inclinations. Int. J. Multiphase Flow 13, 1-12.

Brauner, N., Moalem Maron, D., Rovinsky, J., 1998. A two-fluid model for stratified flows with curved interfaces. Int. J. Multiphase Flow 24, 975-1004.

Brauner, N., Rovinsky, J., Moalem Maron, D., 1996. Determination of the interface curvature in stratified two-phase systems by energy considerations. Int. J. Multiphase Flow 22, 1167-1185.

Cavallini, A., Del Col, D., Doretti, L., Matkovic, M., Rossetto, L., Zilio, C., Censi, G., 2006. Condensation in horizontal smooth tubes: a new heat transfer model for heat exchanger design. Heat Transfer Eng. 27, 31-38.

Crawford, T.J., Weinberger, C.B., Weisman, J., 1985. Two-phase flow patterns and void fractions in downward flow. Part I: steady-state flow patterns. Int. J. Multiphase Flow 11, 761-782.

Fiedler, S., Auracher, H., 2004. Experimental and theoretical investigation of reflux condensation in an inclined small diameter tube. Int. J. Heat Mass Transfer 47, 4031-4043.

Fieg, G.P., Roetzel, W., 1994. Calculation of laminar film condensation in/on inclined elliptical tubes. Int. J. Heat Mass Transfer 37, 619-624.

Fukano, T., Ousaka, A., 1989. Prediction of the circumferential distribution of film thickness in horizontal and near-horizontal gas-liquid annular flows. Int. J. Multiphase Flow 
$15,403-419$.

Geraci, G., Azzopardi, B.J., Van Maanen, H.R.E., 2007. Effect of inclination on circumferential film thickness variation in annular gas/liquid flow. Chem. Eng. Sci. 62, 30323042 .

Grolman, E., Fortuin, J.M.H., 1997. Gas-liquid flow in slightly inclined pipes. Chem. Eng. Sci. 52, 4461-4471.

Hetsroni, G., Mewes, D., Enke, C., Gurevich, M., Mosyak, A., Rozenblit, R., 2003. Heat transfer to two-phase flow in inclined tubes. Int. J. Multiphase Flow 29, 173-194.

Hussein, H.M.S., Mohamad, M.A., El-Asfouri, A.S., 2001. Theoretical analysis of laminar-film condensation heat transfer inside inclined wickless heat pipes flat-plate solar collector. Renewable Energy 23, 525-535.

Laurinat, J.E., Hanratty, T.J., Jepson, W.P., 1985. Film thickness distribution for gasliquid annular flow in a horizontal pipe, in: Two-phase Annular and Dispersed Flows: Selected Papers Presented at the International Symposium on Two-Phase Annular and Dispersed Flows, University of Pisa, Italy, 24-29 June 1984. p. 179.

Lips, S., Meyer, J.P., 2011a. Two-phase flow in inclined tubes with specific reference to condensation: A review. Int. J. Multiphase Flow 37, 845-859.

Lips, S., Meyer, J.P., 2011b. Effect of gravity forces on heat transfer and pressure drops during condensation of R134a, in: Eurotherm Seminar N ${ }^{\circ} 92$. Presqu'illes de Giens, France.

Lips, S., Meyer, J.P., 2012a. Experimental study of convective condensation in an inclined smooth tube. Part I: Inclination effect on flow pattern and heat transfer coefficient. Int. J. Heat Mass Transfer 55, 395-404.

Lips, S., Meyer, J.P., 2012b. Experimental study of convective condensation in an inclined smooth tube. Part II: Inclination effect on pressure drop and void fraction. Int. J. Heat Mass Transfer 55, 405-412.

Nitheanandan, T., Soliman, H.M., 1994. Analysis of the stratified/nonstratified transitional boundary in horizontal and slightly inclined condensing flows. Can. J. Chem. Eng. 72, 26-34.

Nusselt, W., 1916. Die oberflächenkondensation des wasserdampfes. Zeitschrift des Vereins Deutscher Ingenieure 60, 541-546.

Saffari, H., Naziri, V., 2010. Theoretical modeling and numerical solution of stratified condensation in inclined tubes. J. Mech. Sci. Technol. 24, 2587-2596.

Spedding, P.L., Watterson, J.K., Raghunathan, S.R., Ferguson, M.E.G., 1998. Two-phase co-current flow in inclined pipe. Int. J. Heat Mass Transfer 41, 4205-4228.

Taitel, Y., Dukler, A.E., 1976. A model for predicting flow regime transitions in horizontal and near horizontal gas-liquid flow. AIChE J. 22, 47-55.

Thome, J.R., El Hajal, J., Cavallini, A., 2003. Condensation in horizontal tubes. Part 2: new heat transfer model based on flow regimes. Int. J. Heat Mass Transfer 46, 3365-3387.

Ullmann, A., Zamir, M., Gat, S., Brauner, N., 2003. Multi-holdups in co-current stratified flow in inclined tubes. Int. J. Multiphase Flow 29, 1565-1581.

Wang, B.-X., Du, X.-Z., 2000. Study on laminar film-wise condensation for vapor flow in an inclined small/mini-diameter tube. Int. J. Heat Mass Transfer 43, 1859-1868.

Wang, H.S., Rose, J.W., 2006. Film Condensation in Microchannels: Effect of Tube Inclination. ASME Conf. Proc. 2006, 133-137. 


\section{List of figure captions}

Fig. 1. Experimental heat transfer coefficient $\left(G=200 \mathrm{~kg} / \mathrm{m}^{2} \mathrm{~s}\right) .-90^{\circ}$ is vertical downwards, $0^{\circ}$ is horizontal and $90^{\circ}$ is vertical upwards.

Fig. 2. Experimental flow pattern map $\left(G=200 \mathrm{~kg} / \mathrm{m}^{2} \mathrm{~s}\right)$.

Fig. 3. Visualisation of the stratified flow $\left(G=200 \mathrm{~kg} / \mathrm{m}^{2} \mathrm{~s}\right)$.

Fig. 4. Flow pattern map of Crawford et al. (1985) for different inclination angles (R134a, $T_{\text {sat }}=40^{\circ} \mathrm{C}, D=$ $8.38 \mathrm{~mm})$.

Fig. 5. Shape of the liquid-vapour interface.

Fig. 6. Modified model of Taitel and Dukler (1976).

Fig. 7. Scheme of the thermal model.

Fig. 8. Liquid distribution, liquid hold-up and flooded angle as a function of the inclination angle for $G=$ $150 \mathrm{~kg} / \mathrm{m}^{2} \mathrm{~s}$ and for $x=0.3,0.5$ and 0.7 .

Fig. 9. Liquid distribution, liquid hold-up and flooded angle as a function of the inclination angle for $x=0.5$ and for $G=100,150$ and $200 \mathrm{~kg} / \mathrm{m}^{2} \mathrm{~s}$.

Fig. 10. Comparison of the heat transfer coefficient model predictions with the experimental results $(G=$ $\left.200 \mathrm{~kg} / \mathrm{m}^{2} \mathrm{~s}\right)$. Dashed lines for the model predictions mean that the flow is not stratified, according to Crawford $e t$ al. (1985).

Fig. 11. Influence of different assumptions on the model predictions. FFHTC: Falling film heat transfer coefficient $\left(G=200 \mathrm{~kg} / \mathrm{m}^{2} \mathrm{~s} ; x=0.3 ; \Delta T=2 \mathrm{~K}\right)$.

Fig. 12. Influence of the mass flux on the optimum inclination angle $(x=0.3 ; \Delta T=2 \mathrm{~K})$.

Fig. 13. Influence of the vapour quality on the optimum inclination angle $\left(G=200 \mathrm{~kg} / \mathrm{m}^{2} \mathrm{~s} ; \Delta T=2 \mathrm{~K}\right)$.

Fig. 14. Comparison of the pressure drop model predictions with the experimental results $\left(G=200 \mathrm{~kg} / \mathrm{m}^{2} \mathrm{~s}\right)$. Dashed lines for the model predictions mean that the flow is not stratified, according to Crawford et al. (1985). 


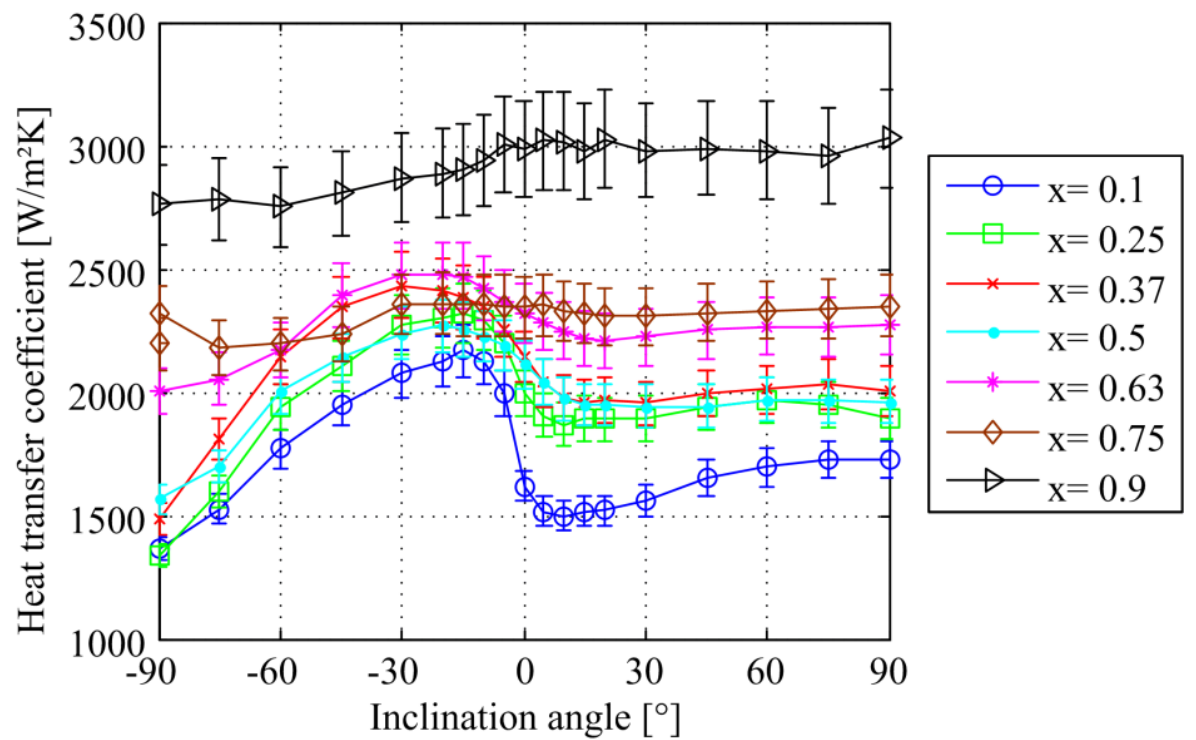

Fig. 1. Experimental heat transfer coefficient $\left(G=200 \mathrm{~kg} / \mathrm{m}^{2} \mathrm{~s}\right)$. $-90^{\circ}$ is vertical downwards, $0^{\circ}$ is horizontal and $90^{\circ}$ is vertical upwards.

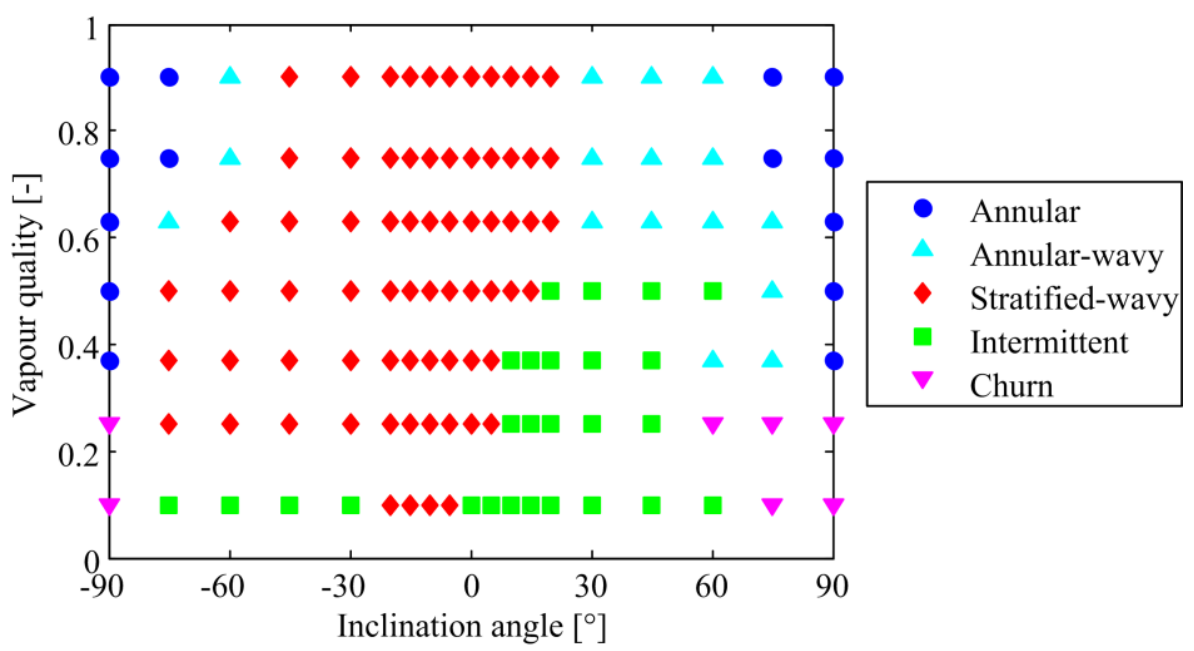

Fig. 2. Experimental flow pattern map $\left(G=200 \mathrm{~kg} / \mathrm{m}^{2} \mathrm{~s}\right)$.

Angle of inclination

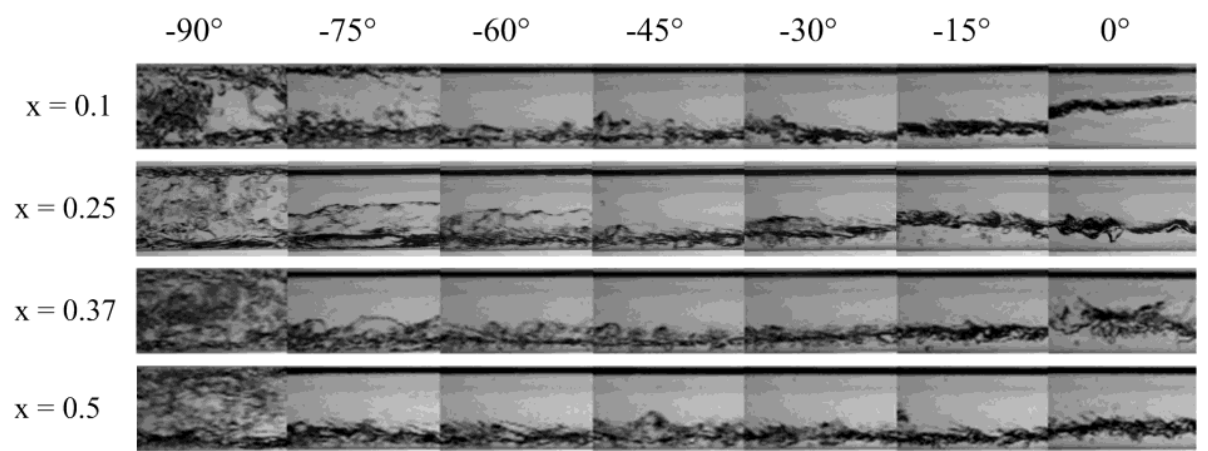

Fig. 3. Visualisation of the stratified flow $\left(G=200 \mathrm{~kg} / \mathrm{m}^{2} \mathrm{~s}\right)$. 


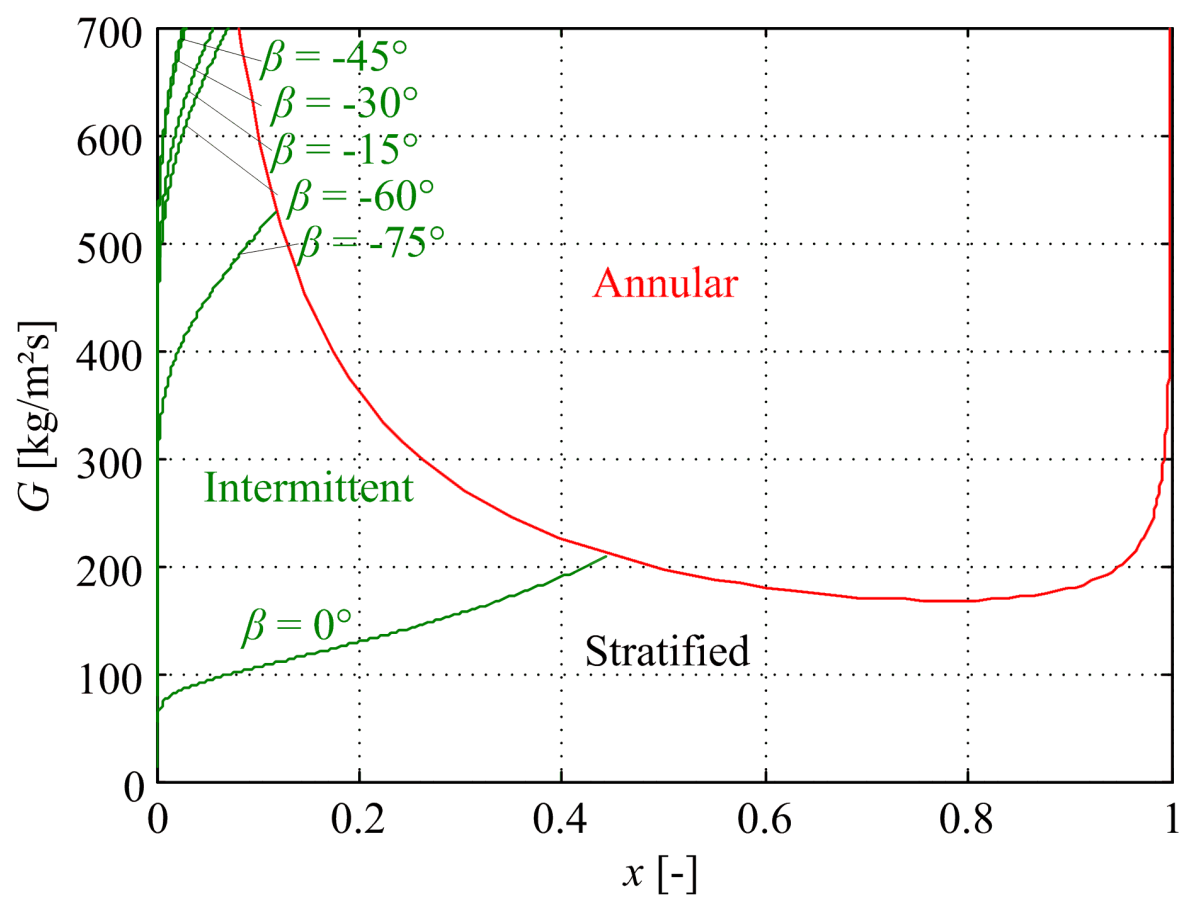

Fig. 4. Flow pattern map of Crawford et al. (1985) for different inclination angles $\left(\mathrm{R} 134 \mathrm{a}, T_{\text {sat }}=40^{\circ} \mathrm{C}, D=\right.$ $8.38 \mathrm{~mm}$ )

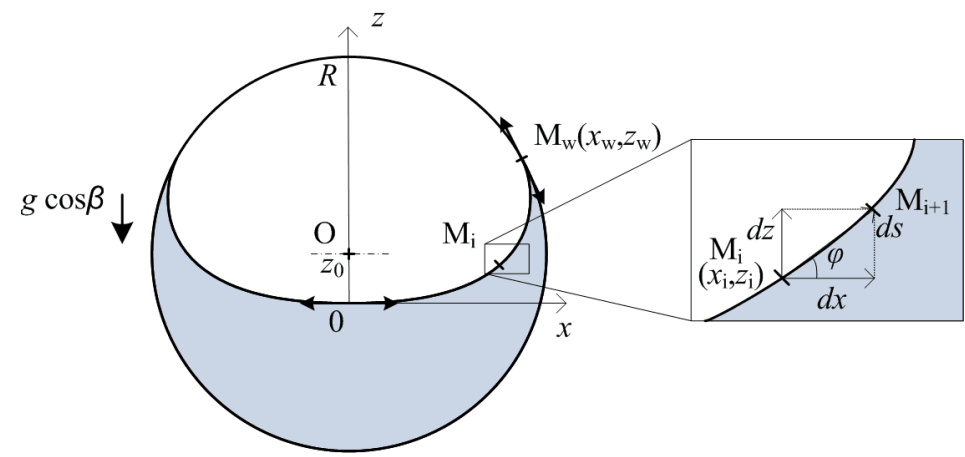

Fig. 5. Shape of the liquid-vapour interface.

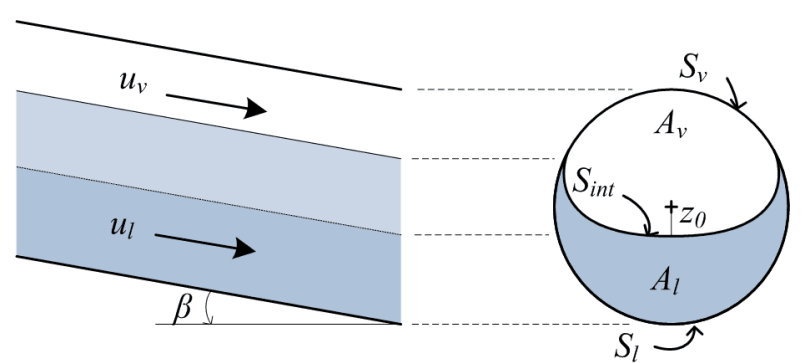

Fig. 6. Modified model of Taitel and Dukler (1976). 


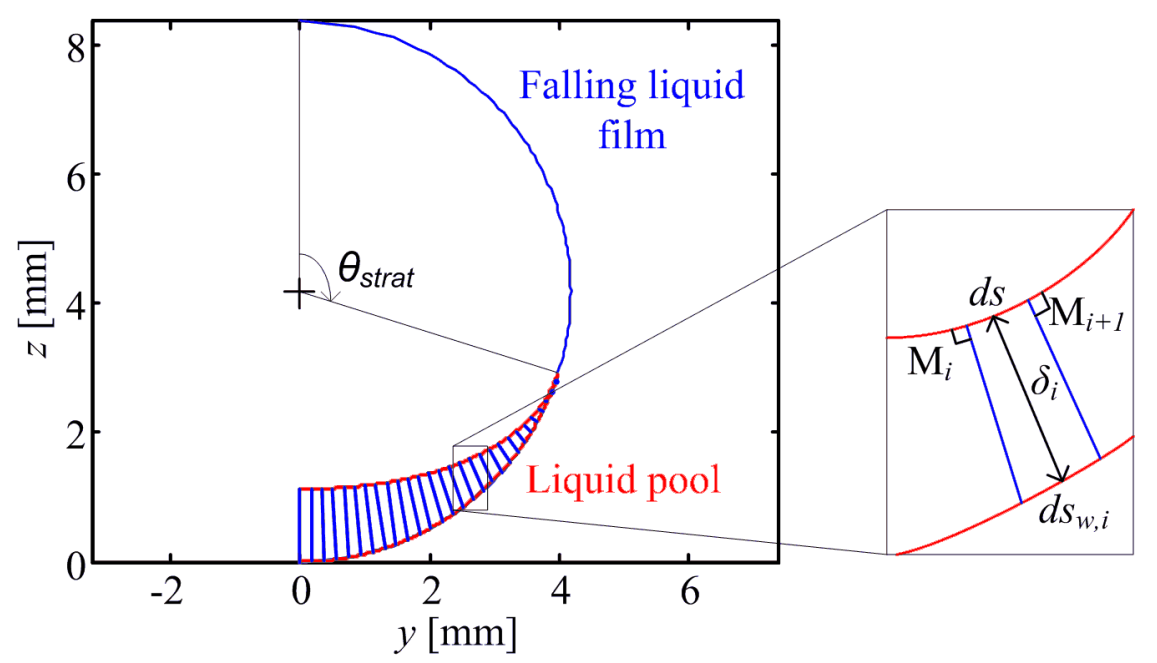

Fig. 7. Scheme of the thermal model.

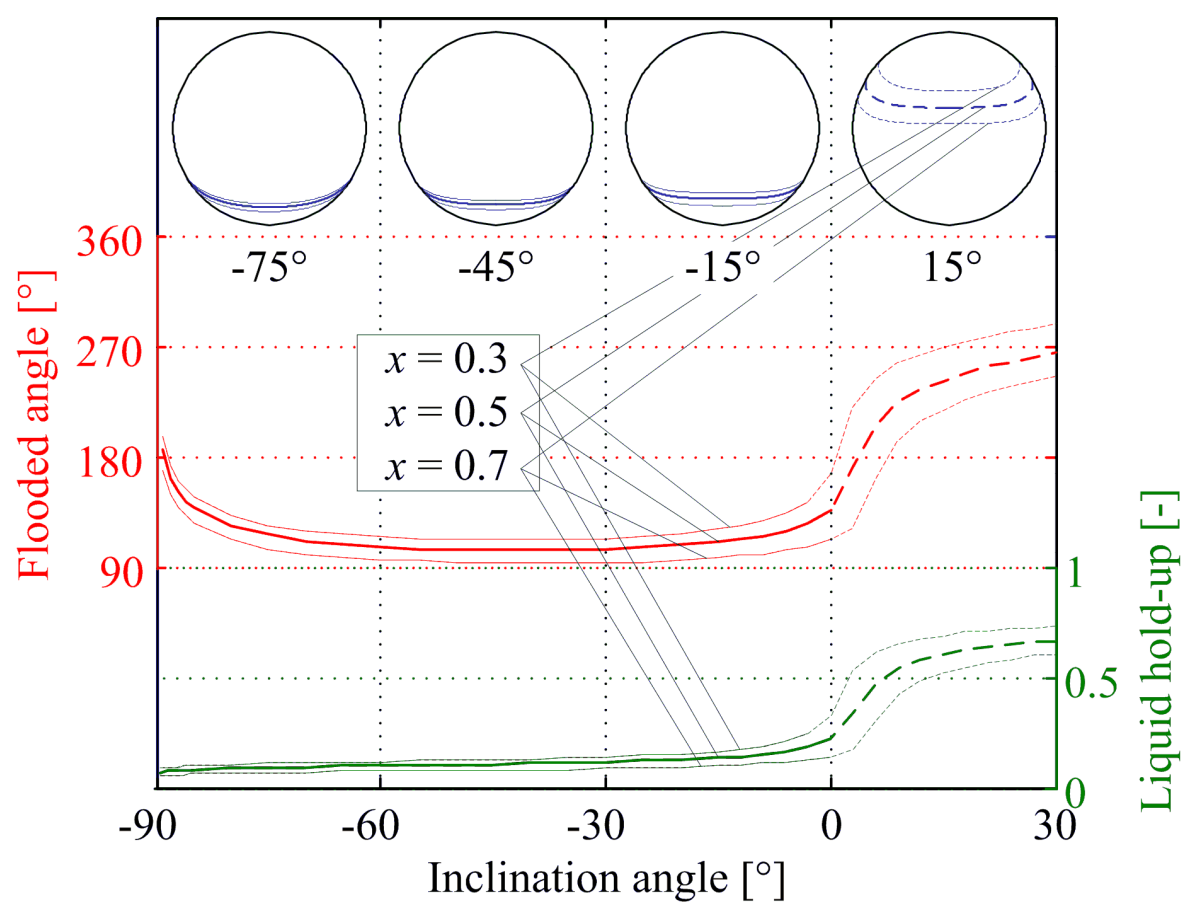

Fig. 8. Liquid distribution, liquid hold-up and flooded angle as a function of the inclination angle for $G=$ $150 \mathrm{~kg} / \mathrm{m}^{2} \mathrm{~s}$ and for $x=0.3,0.5$ and 0.7 . 


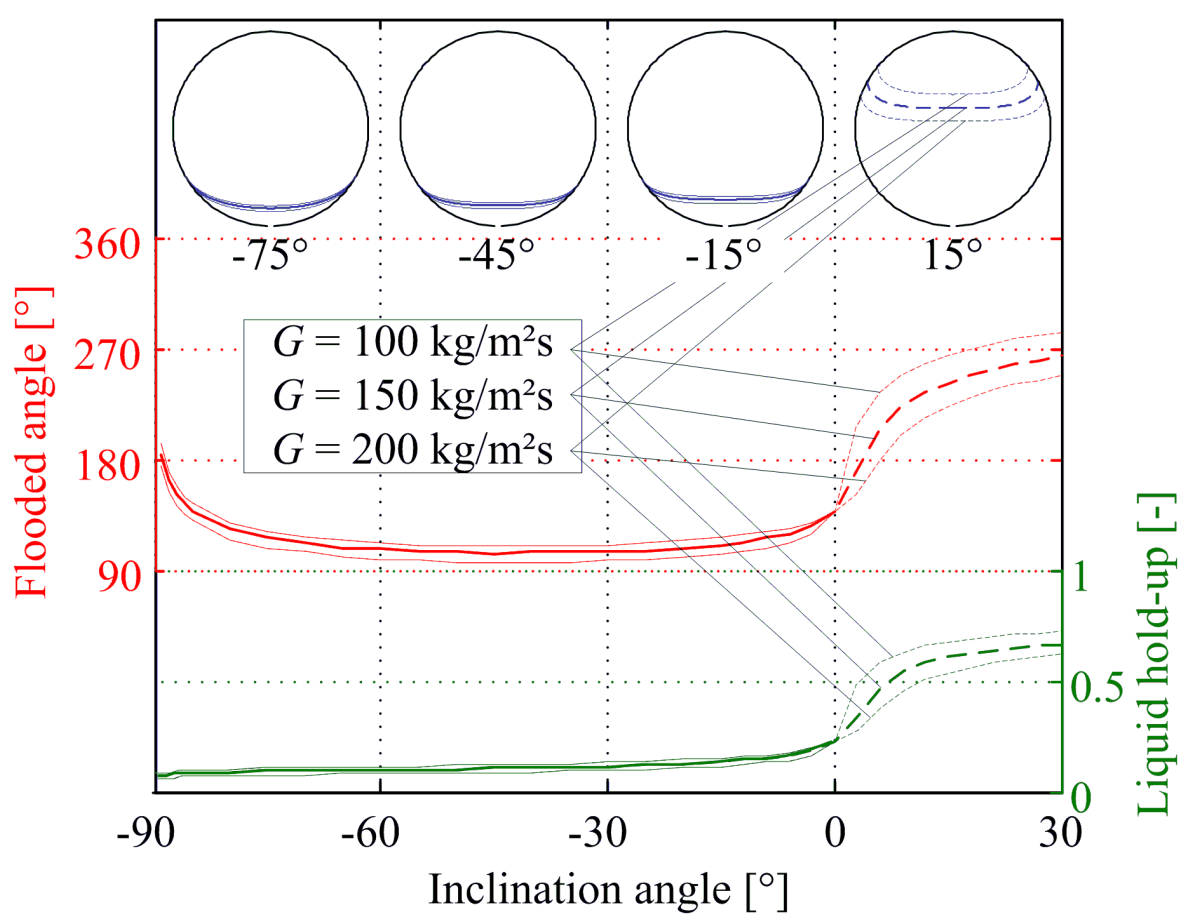

Fig. 9. Liquid distribution, liquid hold-up and flooded angle as a function of the inclination angle for $x=0.5$ and for $G=100,150$ and $200 \mathrm{~kg} / \mathrm{m}^{2} \mathrm{~s}$.

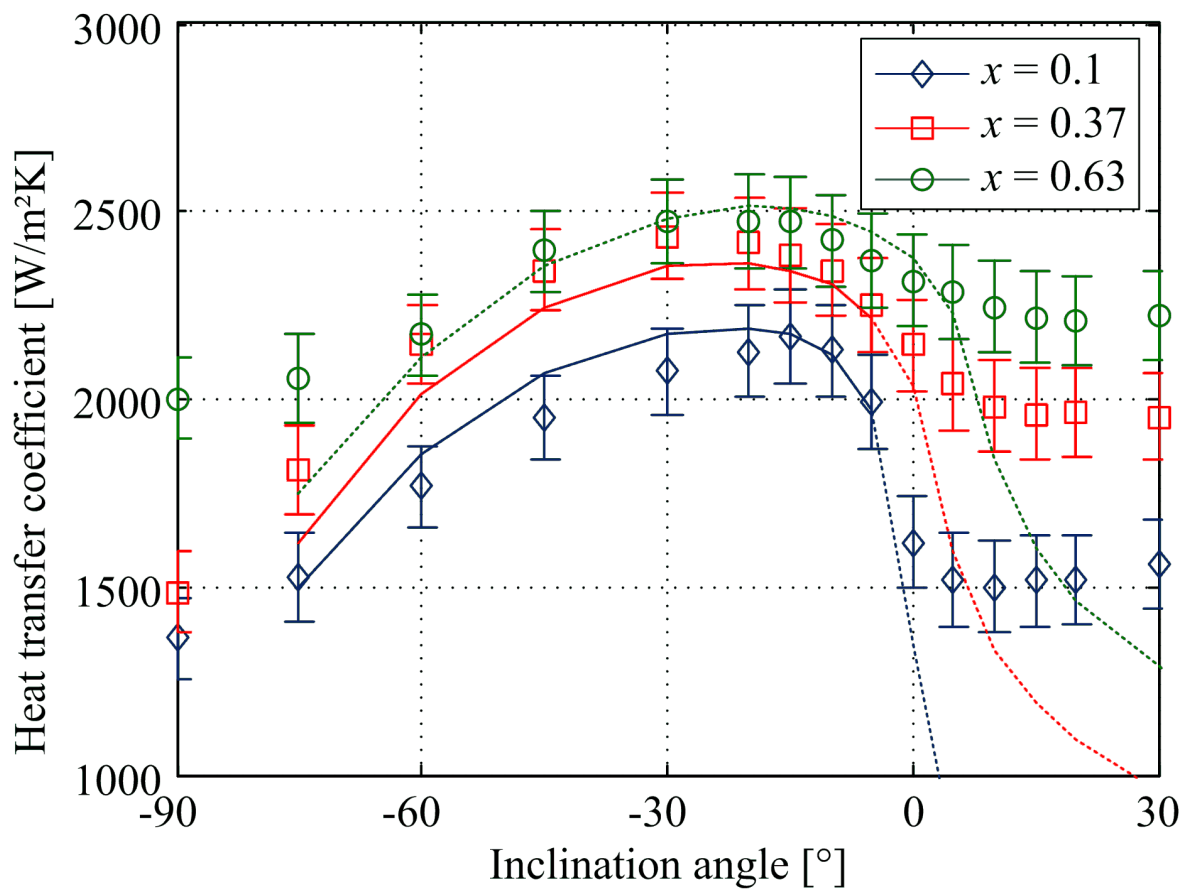

Fig. 10. Comparison of the heat transfer coefficient model predictions with the experimental results $(G=$ $200 \mathrm{~kg} / \mathrm{m}^{2} \mathrm{~s}$ ). Dashed lines for the model predictions mean that the flow is not stratified, according to Crawford $e t$ al. (1985). 


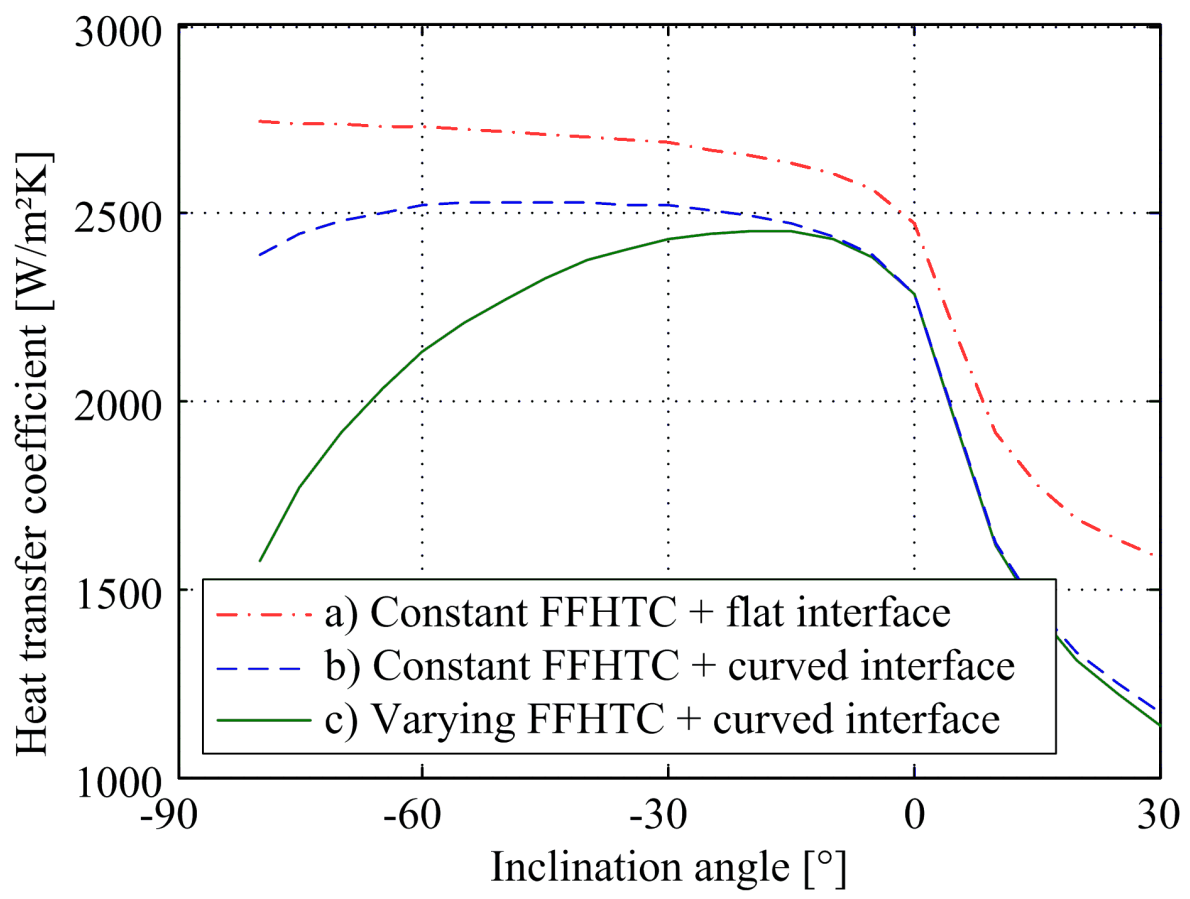

Fig. 11. Influence of different assumptions on the model predictions. FFHTC: Falling film heat transfer coefficient $\left(G=200 \mathrm{~kg} / \mathrm{m}^{2} \mathrm{~s} ; x=0.3 ; \Delta T=2 \mathrm{~K}\right)$.

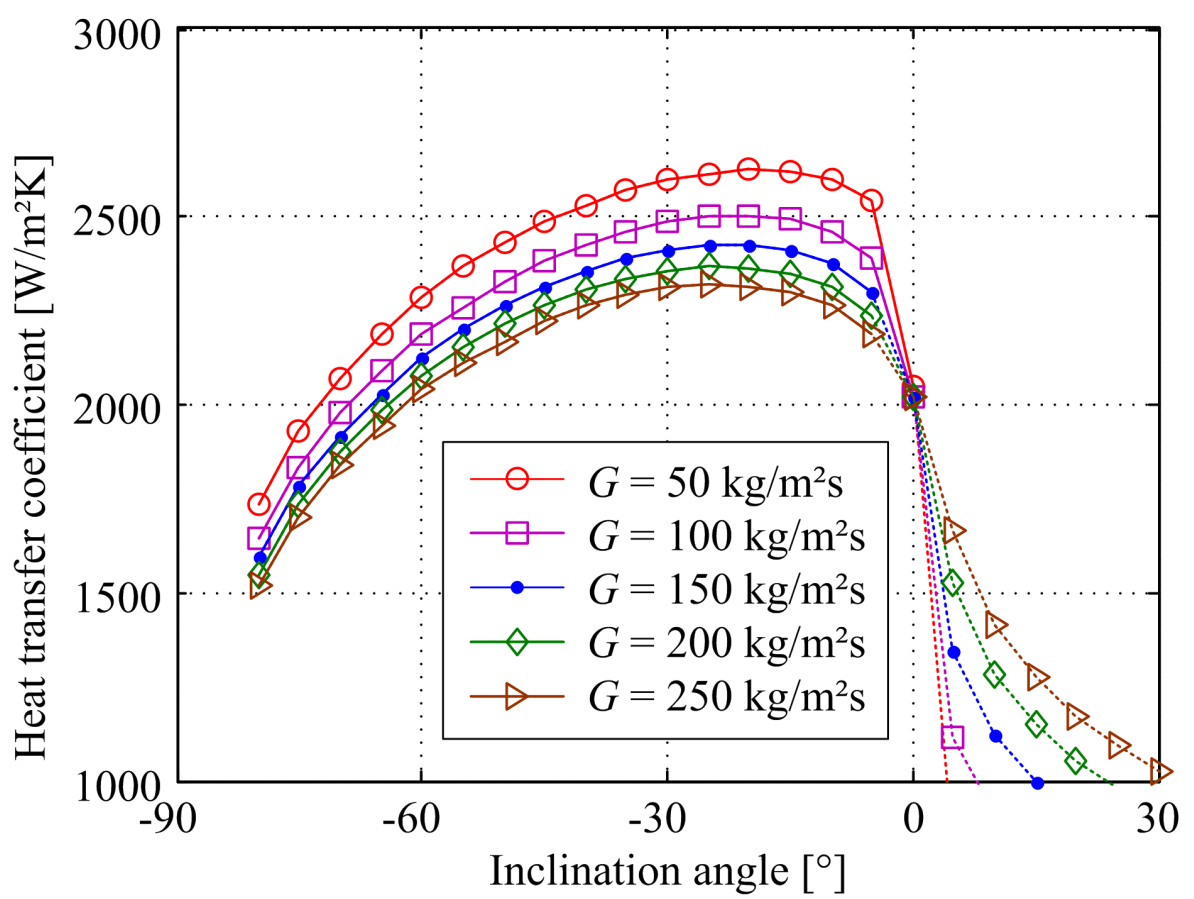

Fig. 12. Influence of the mass flux on the optimum inclination angle $(x=0.3 ; \Delta T=2 \mathrm{~K})$. 


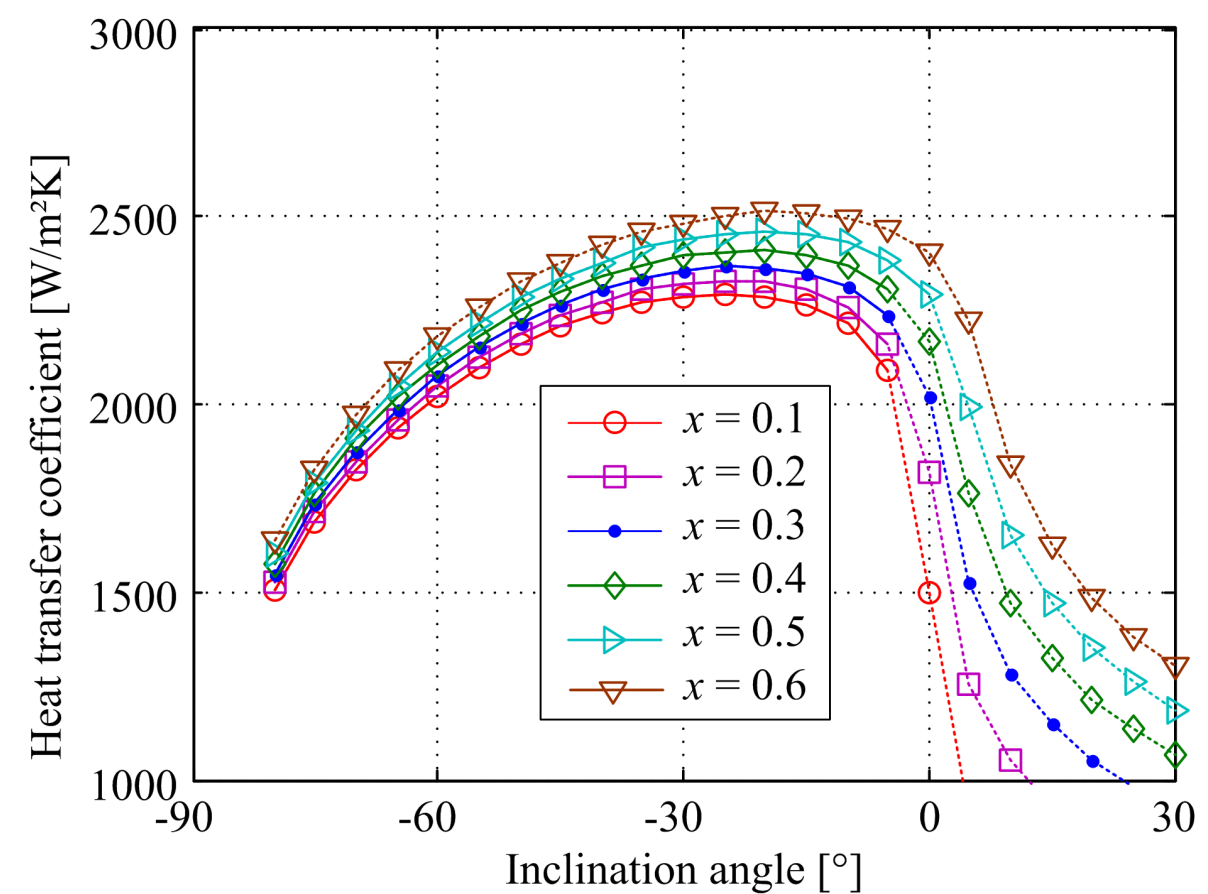

Fig. 13. Influence of the vapour quality on the optimum inclination angle $\left(G=200 \mathrm{~kg} / \mathrm{m}^{2} \mathrm{~s} ; \Delta T=2 \mathrm{~K}\right)$.

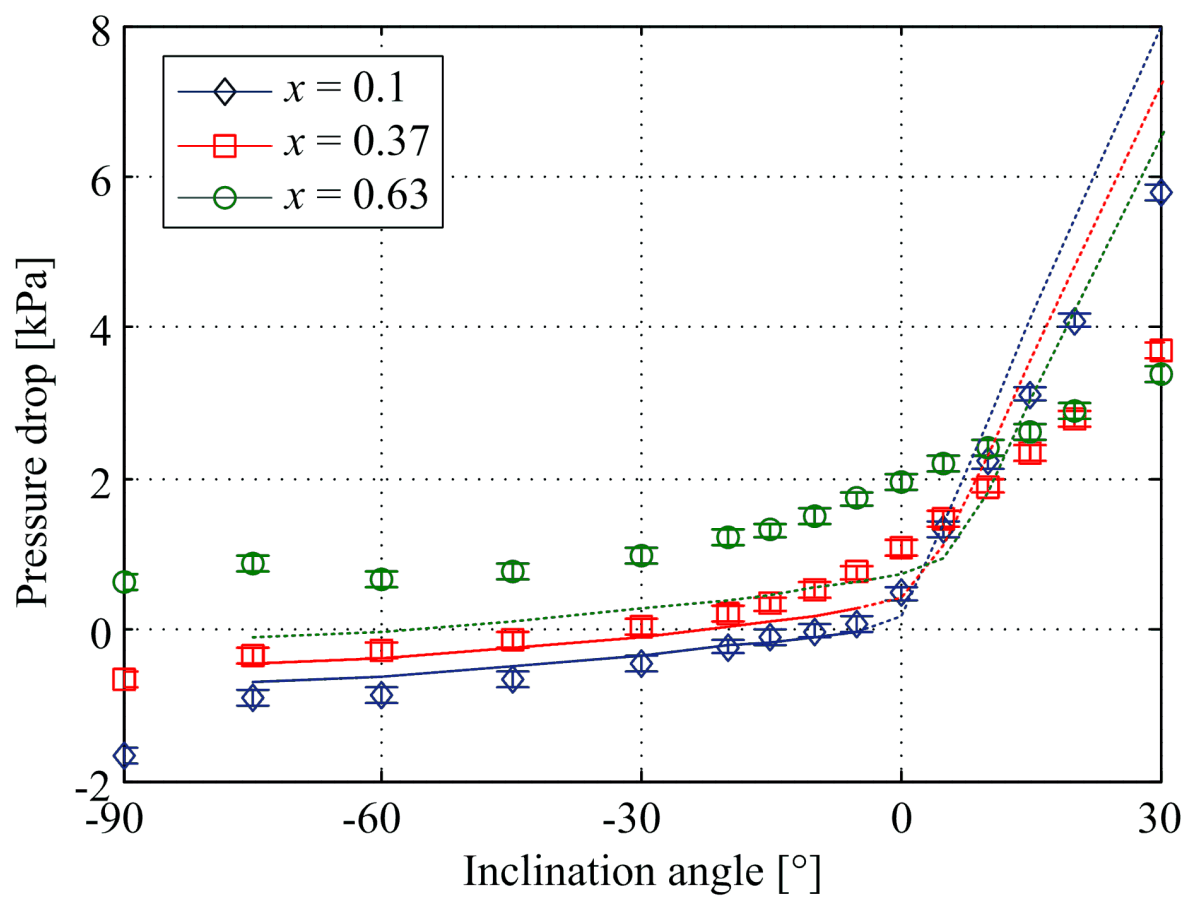

Fig. 14. Comparison of the pressure drop model predictions with the experimental results $\left(G=200 \mathrm{~kg} / \mathrm{m}^{2} \mathrm{~s}\right)$. Dashed lines for the model predictions mean that the flow is not stratified, according to Crawford et al. (1985). 